\title{
Evidence for Autonomic Function and Its Influencing Factors in Subjects With COPD: A Systematic Review
}

\author{
Jibril Mohammed PT MSc, Mira Meeus PT PhD, Eric Derom MD PhD, Hellen Da Silva PT MSc, \\ and Patrick Calders PhD
}

\author{
Introduction \\ Methods \\ Eligibility Criteria \\ Information Sources and Search Strategy \\ Study Selection \\ Qualification of Searchers \\ Data Items and Collection \\ Risk of Bias in Individual Studies \\ Results \\ Study Selection \\ Risk of Bias and Level of Evidence \\ Study Characteristics and Outcome Measures \\ Evidence for Autonomic Function in Subjects With COPD \\ Factors Influencing Autonomic Function in Subjects With COPD \\ Discussion \\ Summary
}

Cardiovascular autonomic neuropathy is one of the factors implicated in the high morbidity and mortality rate in patients with COPD. Thus, several studies and nonsystematic reviews have increasingly reported autonomic function impairment in these subjects. For a better understanding, this systematic review was performed to evaluate not only the evidence for autonomic function impairment, but also factors influencing it. The results of the studies reviewed showed a strong level of evidence to support the impairment of heart rate variability in the time domain. A similar evidence level was also found to support impairment in baroreceptor sensitivity and muscle sympathetic nerve activity. Furthermore, this review identified physical activity level, muscle function, and circadian rhythm as the major influencing factors (strong evidence) of autonomic function in subjects with COPD. However, no definite conclusion could be reached for factors such as dyspnea, anxiety, body composition, pulmonary function, age, breathing frequency, ventilatory effort, quality of life, and disease severity due to limited, conflicting, or lack of existing evidence. The results of this review highlight relevant clinical messages for clinicians and other health-care providers regarding the role autonomic function can play as an important physiological marker for prognostication and stratification. Hence, autonomic function outcomes should be identified and considered during management of patients with COPD. Moreover, this review can serve as basis for future research aimed at assessing the interventions for autonomic function abnormalities in these patients. Key words: nervous system disease; autonomic; sympathetic; parasympathetic; chronic obstructive; pulmonary disease; review. [Respir Care 2015;60(12):1841-1851. (C) 2015 Daedalus Enterprises] 


\section{Introduction}

COPD is a highly prevalent cause of disability and mortality characterized by air-flow limitation that is not fully reversible. ${ }^{1}$ Patients with COPD have features that encompass several body systems, such as inflammation of the airways, cachexia or obesity, structural and functional changes in respiratory and peripheral muscles, arrhythmias, fatigue, dyspnea, poor quality of life (QOL), reduced exercise capacity, depression, anxiety, and sleep disturbances. ${ }^{1-8}$

More recently, COPD has been reported to adversely affect the autonomic nervous system.2,5,6 Consequently, autonomic function in patients with COPD has received a considerable amount of attention in the literature. ${ }^{2-7,9-11}$ The autonomic nervous system controls and regulates the internal physiology of the body and plays a very important role in the pathophysiology of COPD. It consists of 2 branches (sympathetic and parasympathetic), both of which exert antagonistic effects on most bodily functions and also contribute to homeostasis in the body. ${ }^{12}$ Moreover, the autonomic nervous system is responsible for maintaining involuntary vital parameters, including blood pressure, heart rate, respiration, gastrointestinal secretions, and temperature control.

Autonomic function can be directly assessed by monitoring and testing certain specific markers of the neurophysiological condition of the autonomic nervous system. These parameters include heart rate variability in timeand/or frequency-domain analysis, baroreceptor sensitivity, muscle sympathetic nerve activity, and sympathetic skin response. Heart rate variability, which is the variability in time and/or frequency of successive $\mathrm{R}$ waves of the heartbeats, reflects the integration between the cardiovascular system and the mechanisms it regulates. Moreover, HRV has been well recognized as a parameter for assess-

\footnotetext{
Mr Mohammed, Dr Meeus, Ms Da Silva, and Dr Calders are affiliated with the Department of Rehabilitation Sciences and Physiotherapy, Ghent University, Ghent, Belgium. Dr Derom is affiliated with the Department of Respiratory Medicine, Ghent University Hospital, Ghent University, Ghent, Belgium. Mr Mohammed is also affiliated with the Department of Physiotherapy, Bayero University Kano, Kano, Nigeria.
}

Supplementary material related to this paper is available at http:// www.rcjournal.com.

Mr Mohammed was supported by a PhD study scholarship from the Tertiary Education Trust Fund (TETFund), Nigeria. The authors have disclosed no conflicts of interest.

Correspondence: Jibril Mohammed PT MSc, Department of Rehabilitation Sciences and Physiotherapy, Ghent University, 3B3, De Pintelaan 185, 9000 Ghent, Belgium. E-mail: jibril.mohammed@ugent.be.

DOI: $10.4187 /$ respcare. 04174 ing autonomic function and quantifying sympathovagal balance for many decades. ${ }^{1,13}$ Additionally, baroreceptor sensitivity (which reflects the short-term regulation of the cardiovascular system), muscle sympathetic nerve activity (which shows the degree of sympathetic activity in muscle nerves), and sympathetic skin response (which reflects the sudomotor function of the unmyelinated sympathetic nerves) are reported to be reliable measures of autonomic function. ${ }^{14-16}$

The available data in the literature suggest that autonomic function parameters of subjects with COPD may be severely impaired. ${ }^{17-20}$ Nevertheless, for a better understanding, a systematic evaluation of the existing literature is necessary. Also, there is a need to evaluate the factors that are associated with autonomic function in patients with COPD because this has not been clearly elucidated in literature. Therefore, this systematic review evaluated (1) the evidence on the autonomic function of subjects with COPD and (2) the factors associated with a possible altered autonomic function.

\section{Methods}

This systematic review is reported in accordance with PRISMA (Preferred Reporting Items for Systematic Reviews and Meta-Analyses) guidelines. ${ }^{21}$

\section{Eligibility Criteria}

To be included in this systematic review, the studies had to report on either the autonomic function (outcomes) of subjects with COPD (population) versus healthy participants (comparator) and/or the relationship between autonomic function and influencing factors. Only randomized control trials or patient control or cohort studies were retained.

\section{Information Sources and Search Strategy}

To identify relevant articles, the databases of PubMed, Embase, and Web of Science were searched. Only articles published between January 2004 and May 2014 were included. The search strategy was based on a combination of the following key words: autonomic function OR autonomic dysfunction OR heart rate variability OR baroreceptor sensitivity OR muscle sympathetic nerve activity OR sympathetic skin response AND chronic obstructive pulmonary disease OR COPD. For the PubMed database, key words were also converted to possible MeSH terms. The search strategy for the Web of Science was done in the topic field using the key words autonomic function AND COPD. For the Embase database, the search terms were: autonomic AND function AND COPD. The search strategy for all databases was also filtered based on article 
type (clinical trial), language (English), and species (human). Additionally, a secondary search of the reference list of the included studies was undertaken to make the review as complete as possible.

\section{Study Selection}

To be included in the review, the following inclusion criteria had to be fulfilled for each article. (1) Subjects had to be clinically diagnosed with COPD (explicitly stated). (2) The autonomic function parameters should comprise at least one of the following parameters for studies comparing subjects with COPD and healthy controls and/or reporting relationships between any of the parameters with influencing factors: (a) heart rate variability in a time and/or frequency domain. The time domain may consist of (i) the square root of the mean of the sum of the squares of differences (root mean square of successive differences [RMSSD]), (ii) the RR interval (RRi), (iii) the SD of the averages of NN intervals in all 5-min segments of the entire recording (SDANN), (iv) the SDs of all NN intervals (SDNN), (v) the total number of differences between adjacent RRi above $50 \mathrm{~ms}\left(\mathrm{sNN}_{50}\right)$, (vi) the percentage of RRi that differ from each other by $>50 \mathrm{~ms}\left(\mathrm{pNN}_{50}\right)$, (vii) the ratio between the shortest $\mathrm{RRi}$ around the 15 th beat and the longest $\mathrm{RRi}$ around the 30th beat (30:15 ratio), (viii) the difference in heart rate during inspiration and expiration $(\Delta \mathrm{IE})$, (ix) the triangular interpolation of the $\mathrm{RRi}$, (x) the SD of instantaneous beat-to-beat variability $\left(\mathrm{SD}_{1}\right)$, (xi) the $\mathrm{SD}$ in long term of the $\mathrm{RRi}\left(\mathrm{SD}_{2}\right)$, (xii) the Valsalva ratio (the ratio of the longest $\mathrm{RRi}$ after release from the maneuver to the shortest RRi during the maneuver), (xiii) the ratio of the longest RRi during the 5 beats before lying down to the shortest RRi during the 10 beats after lying down (S/L ratio), (xiv) the SD of the RRi, (xv) the variability triangular index, (xvi) the average/mean NN interval, and (xvii) the coefficient of variation of the RRi. The frequency (the density of beat-to-beat oscillation in the $\mathrm{RRi})$ domain was recorded in the high $(0.15-0.4 \mathrm{~Hz})$, low $(0.04-0.15 \mathrm{~Hz})$, and very low $(0.00-0.04 \mathrm{~Hz})$ frequency bands and may be described using parameters such as: (i) total power (TP), (ii) high frequency (HF), (iii) very-low frequency (VLF), (iv) low frequency (LF), and (v) low-high frequency ratio (LF/HF). Additionally, the spectral components may be expressed as normalized units (nu), which is the absolute power/total power - VLF power $\times 100$ (depicted as LFnu or HFnu); (b) the baroreceptor sensitivity expressed in $\mathrm{ms} / \mathrm{mm} \mathrm{Hg}$; (c) the muscle sympathetic nerve activity expressed in burst frequency (bursts/min) and/or burst incidence (bursts/100 heartbeats); and (d) the sympathetic skin response expressed in terms of latency, area, and amplitude in $\mathrm{s}, \mathrm{mV} / \mathrm{s}$, and $\mathrm{mV}$, respectively. (3) The article had to be published in English, and (4) it had to be a full-text original research report.
Initially, all search results were screened based on title and abstract. Thereafter, the full-text articles of studies that were considered potentially eligible and relevant were retrieved. All full-text articles were evaluated to ascertain whether they fulfilled the inclusion criteria. If an article did not fulfill all 4 criteria, it was excluded from the review.

\section{Qualification of Searchers}

The literature was searched and screened by JM and PC (who has published systematic reviews). ${ }^{12,22-24}$

\section{Data Items and Collection}

Information extracted from each of the included studies is presented in Table 1 (see the supplementary materials at http://www.rcjournal.com). This table provides: (1) author and year, (2) sample size and characteristics of participants, (3) inclusion and exclusion criteria, (4) results of autonomic function parameter comparison with controls, and (5) results of influencing factors.

\section{Risk of Bias in Individual Studies}

To establish the validity of the selected articles, the risk of bias (methodological quality) in the articles was determined using specific checklists per design provided by the Dutch Cochrane Centre. The methodological quality was determined by asking 7, 9, and 10 questions for the patient control and cohort studies and randomized control trials, respectively, from the checklists as shown in Table 2 (see the supplementary materials at http://www.rcjournal.com).

Methodological quality was assessed by 2 researchers (JM and HDS) who were not acquainted with each other's evaluation at first. We scored each question as either + (informative description of the issue and the study meets the criterion) or - (the study does not meet the criterion).

After rating the selected articles, the results of both researchers were compared, and the differences were analyzed. In case of disagreement, the reviewers screened the manuscript a second time, and each point of difference was discussed. Both reviewers also had the opportunity to argue and to convince one another to obtain a consensus. When a consensus could not be reached, a third and final opinion was provided by PC. Each study received a total method score, which was the sum of all positive $(+)$ ratings from the checklist questions. For uniformity across different designs, the overall method scores were converted to percentages. A study was considered to be high quality if the methodological quality score was $\geq 60 \%$ and low quality if the methodological quality was $<60 \% .^{25}$

The evidence listings for the outcomes were classified according to the methods used by Bakker et al. ${ }^{25}$ The 


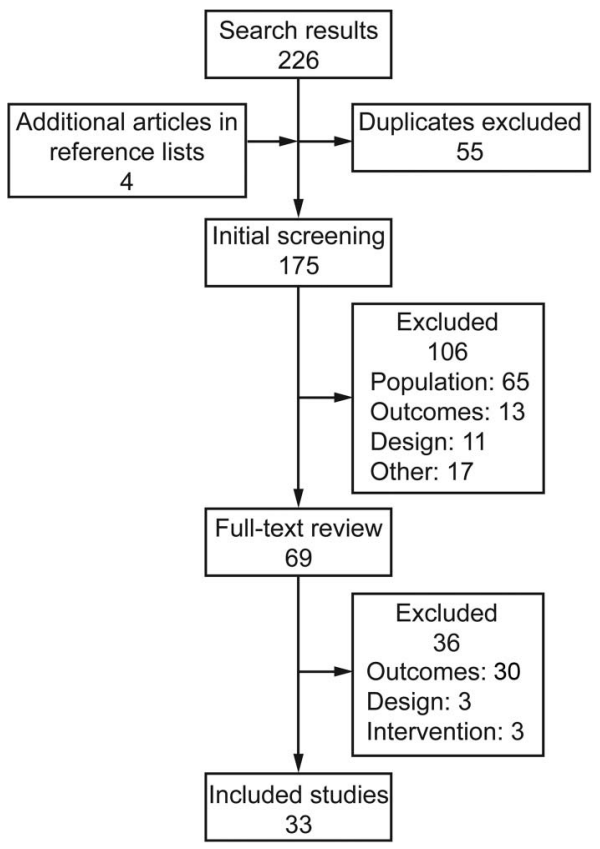

Fig. 1. Flow chart.

possible evidence levels are: strong, moderate, limited, conflicting evidence, and no evidence. Strong evidence represents consistent findings reported in at least 2 highquality studies. Moderate evidence connotes consistent findings in one high- and one low-quality study or at least 2 independent studies of low quality. Limited evidence suggests that only one study was available. Conflicting evidence connotes inconsistent findings in the available studies. No evidence refers to when no study that reported any autonomic function outcomes was found. Additionally, findings in the studies were considered consistent only if at least $75 \%$ of the available studies reported the same conclusion for the outcome in question.

\section{Results}

\section{Study Selection}

A total of 154 studies were identified from the database and reference search. After the first and second screening, 33 articles were included in the review for quality synthesis as shown in Figure 1.

\section{Risk of Bias and Level of Evidence}

The risk of bias and the level of evidence showed that, in most cases (263 of 277 items), the 2 researchers (JM and HDS) agreed in the quality assessment. After the second review, the researchers reached a consensus for 11 of the 14 items on which they initially disagreed.

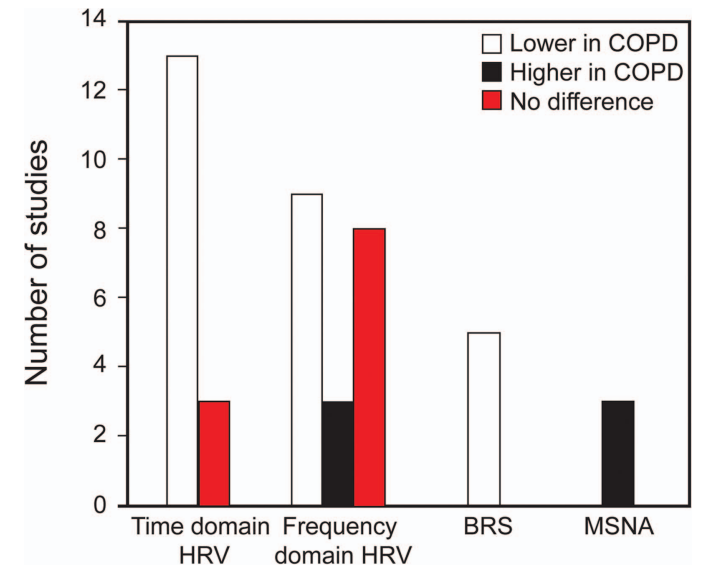

Fig. 2. Trend of autonomic function results of the reviewed studies. $\mathrm{HRV}=$ heart rate variability; BRS = baroreceptor sensitivity; MSNA = muscle sympathetic nerve activity.

The remaining 3 questions were scored by PC. The evaluation criteria and final scores for the studies are presented in Table 2 (see the supplementary materials at http://www.rcjournal.com).

After converting to percentages, $82 \%$ of the studies scored as high methodological quality (ie, $>60 \%$ from the checklist score percent) because only 6 studies were of low methodological quality scores..$^{10,26-30}$

\section{Study Characteristics and Outcome Measures}

The characteristics (study size, participants, inclusion criteria, autonomic function parameters, and influencing factors) for each study are presented in Table 1 (see the supplementary materials at http://www.rcjournal.com). Of the 20 studies that compared the autonomic function between subjects with COPD and healthy controls, 15 studies reported heart rate variability as outcome, whereas baroreceptor sensitivity ${ }^{10,11,19,27,31}$ and muscle sympathetic nerve activity ${ }^{31-33}$ were the reported outcomes in 5 and 3 studies, respectively. Only one study assessed the sympathetic skin response. ${ }^{14}$ Accordingly, heart rate variability was expressed in $\mathrm{ms}$ or $\mathrm{ms}^{2}$, muscle sympathetic nerve activity was expressed as bursts/min and/or bursts/100 heartbeats, and baroreceptor sensitivity was expressed as $\mathrm{ms} / \mathrm{mm} \mathrm{Hg}$. Furthermore, an overview (trend) of the autonomic function outcomes for time and frequency domain heart rate variability, baro receptor sensitivity, and muscle sympathetic nerve activity of subjects with COPD in the included studies is illustrated in Figure 2.

\section{Evidence for Autonomic Function in Subjects With COPD}

Heart Rate Variability. Fifteen studies of high methodological quality investigated the differences in heart rate 
variability values between subjects with COPD and healthy controls. $3,10,13,19,34-44$ Most of these studies reported significantly lower heart rate variability in subjects with COPD. Specifically, the time-domain parameters in most of the studies (12 of 15) showed that subjects with COPD had lower heart rate variability compared with healthy controls. The studies reported that parameters such as $\mathrm{sNN}_{50},{ }^{35}$ average $\mathrm{NN}$ interval, ${ }^{44} \mathrm{pNN}_{50},{ }^{35,44}$ SDANN,, 35 SDNN, $, 3,35,38,43,44$ SDNN index, ${ }^{35}$ RMSSD $, 3,35,38,43,44$ RRi, ${ }^{19}$ $\mathrm{SD}_{1},{ }^{13,43} \mathrm{SD}_{2}, 13,43 \mathrm{SD}_{1} / \mathrm{SD}_{2},{ }^{43}$ triangular interpolation of the $\mathrm{RRi},{ }^{35}$ and the variability triangular index ${ }^{13}$ were all reduced (or negatively altered) in subjects with COPD compared with healthy controls $(P<.05)$. Furthermore, other time-domain values reported to be impaired in subjects with COPD include the SD of the RRi, ${ }^{34}$ coefficient of variation of the $\mathrm{RRi}^{34}$ Valsalva ratio, ${ }^{37,42} 30: 15$ ratio, ${ }^{37,42} \mathrm{~S} / \mathrm{L}$ ratio, ${ }^{42}$ and $\Delta \mathrm{IE} .{ }^{37}$ However, 3 studies reported comparable time-domain parameters between subjects with COPD and healthy controls. ${ }^{36,39,41}$

The frequency-domain values for heart rate variability showed more variation across the studies. Lower frequencydomain values were reported in some studies for LF, ${ }^{3,34,36,38,39,43,44} \mathrm{HF}, 3,34,38,43,44 \mathrm{LF} / \mathrm{HF},{ }^{39,41} \mathrm{LFnu},{ }^{39,44}$ and $\mathrm{TP},{ }^{34,40,44}$ whereas other investigators reported comparable findings for $\mathrm{LF},{ }^{10,41} \mathrm{HF}, 10,36,39,41 \mathrm{LF} / \mathrm{HF},{ }^{34,38,40,44}$ LFnu, ${ }^{10,34,38,44}$ and HFnu in subjects with COPD compared with their healthy counterparts. ${ }^{10,34,38,44}$ Additionally, higher values were reported in a few studies for LF, ${ }^{40}$ $\mathrm{HF},{ }^{40} \mathrm{LF} / \mathrm{HF},{ }^{43}$ and HFnu ${ }^{39}$ in subjects with COPD compared with healthy controls.

Based on the quality and level of evidence and the results from the majority of the studies reviewed, there is strong evidence to support impairment of time-domain heart rate variability in subjects with COPD. For frequencydomain heart rate variability, the evidence is inconsistent.

Baroreceptor Sensitivity. Five studies of low 10,27 and high $^{11,19,31}$ methodological quality reported that baroreceptor sensitivity was significantly depressed in subjects with COPD compared with healthy controls. Across all of the studies, the baroreceptor sensitivity of subjects with COPD ranged from $1.9 \pm 2.92$ to $8.9 \pm 1.70 \mathrm{~ms} / \mathrm{mm} \mathrm{Hg}$, whereas that of the healthy controls ranged from $6.2 \pm$ 2.26 to $14.3 \pm 2.00 \mathrm{~ms} / \mathrm{mm} \mathrm{Hg}$. Raupach et $\mathrm{al}^{31}$ reported that baroreceptor sensitivity in subjects with mild COPD was significantly lower compared with controls (5.0 \pm 0.60 vs $9.3 \pm 1.10 \mathrm{~ms} / \mathrm{mm} \mathrm{Hg}$ ). Similarly, significantly lower values were also reported for subjects with different stages (moderate to severe) of COPD in studies by Costes et $\mathrm{al}^{10}(2.7 \pm 1.50$ vs $7.8 \pm 4.90 \mathrm{~ms} / \mathrm{mm} \mathrm{Hg}, P<.01)$, Bartels et al ${ }^{11}(1.9 \pm 2.92$ vs $6.2 \pm 2.26 \mathrm{~ms} / \mathrm{mm} \mathrm{Hg}, P<$ $.001)$, and Haider et $\mathrm{al}^{19}(6.2 \pm 1.05$ vs $10.7 \pm 1.65$ $\mathrm{ms} / \mathrm{mm} \mathrm{Hg}, P=.03$ ). Another study on subjects with mild COPD also showed baroreceptor sensitivity depression compared with healthy age-matched controls $(8.9 \pm 1.70$ vs $14.3 \pm 2.00 \mathrm{~ms} / \mathrm{mm} \mathrm{Hg}$ ). ${ }^{27}$ Based on the quality and level of evidence, there is strong evidence to support baroreceptor sensitivity depression in subjects with COPD.

Muscle Sympathetic Nerve Activity. Three studies of high methodological quality compared the muscle sympathetic nerve activity between subjects with COPD and healthy controls, and all concluded that muscle sympathetic nerve activity was impaired in subjects with COPD. ${ }^{31-33}$ The values in bursts/100 heartbeats ranged between $55 \pm 4.7$ to $86.9 \pm 2.0$ for COPD and $33 \pm 6.0$ to $49 \pm 6.0$ for healthy controls, respectively. In one study, subjects with COPD were reported to present with significantly elevated muscle sympathetic nerve activity compared with healthy controls (burst frequency of $62 \pm 2.0$ vs $29 \pm 3.0$ bursts/min, which corresponds to a burst incidence of $86 \pm 2.0$ vs $49 \pm 6.0$ bursts/100 heartbeats). ${ }^{32}$ Furthermore, similar findings were reported in 2 other studies that reported baseline muscle sympathetic nerve activity to be significantly elevated in subjects with COPD compared with healthy controls $(P<.05))^{31,33}$ Based on the quality and level of evidence, there is strong evidence to support elevation of muscle sympathetic nerve activity in subjects with COPD.

Sympathetic Skin Response. Only one study of high methodological quality reported the sympathetic skin response of subjects with COPD. ${ }^{17}$ The outcome demonstrated that the sympathetic skin response was impaired in subjects with COPD compared with healthy controls. The evidence supporting impairment of the sympathetic skin response in subjects with COPD is limited.

\section{Factors Influencing Autonomic Function in Subjects With COPD}

Disease Severity (Stage), Duration, and Exacerbation. Four studies of low ${ }^{26,29}$ and high ${ }^{37,45}$ methodological quality evaluated the influence of disease severity on autonomic function in subjects with COPD. Two of the studies concluded that disease severity had a significant effect on autonomic function. ${ }^{26,37}$ Chhabra and $D^{37}$ revealed that autonomic neuropathy was observed more often in subjects with moderate-to-severe COPD compared with subjects with mild COPD $(P<.05)$. Antonelli Incalzi et $a^{26}$ also reported significant correlations between LF/HFnu and the indices of disease severity. Conversely, the other 2 studies reported that disease severity did not influence autonomic function. Tug et $\mathrm{a}^{45}$ found no significant difference between mild and moderate-to-severe COPD groups for the isolated parasympathetic, sympathetic, or mixed form $(P>.05)$. Similarly, Ramos et al ${ }^{29}$ reported that different stages of COPD (Global Initiative for Chronic 
Obstructive Lung Disease [GOLD] stages I-III) had no influence on RMSSD.

Two studies of high methodological quality assessed the influence of disease duration on autonomic function in subjects with COPD, and both studies concluded that it had none $(P>.05) \cdot{ }^{17,45}$ Furthermore, one study of high methodological quality indicated that COPD exacerbation was associated with a significant increase in LF, HF, $\mathrm{LF} / \mathrm{HF}$, and TP $(P<.05)$ compared with subjects with stable COPD and/or healthy controls. ${ }^{40}$

The evidence supporting the effect of disease severity on autonomic function is inconsistent. However, there is strong evidence to support that disease duration has no influence on autonomic function, and there is limited evidence to support that exacerbation influences autonomic function in subjects with COPD.

Pulmonary Function and Respiratory Parameters. Eight studies of low ${ }^{10,26}$ and high 1,17,19,34,37,41 methodological quality reported a relationship between spirometric indices $\left(\mathrm{FEV}_{1}\right.$, percent-of-predicted $\left.\mathrm{FEV}_{1}, \mathrm{FEV}_{1} / \mathrm{FVC}\right)$ and autonomic function in subjects with COPD. Three of these studies reported that there were no significant correlations between pulmonary function variables and autonomic function. ${ }^{1,10,34}$ In contrast, the remaining 5 studies reported significant correlations between the lung function variables and autonomic function parameters. ${ }^{26,17,19,37,41}$ Weak correlations were found between percent-of-predicted $\mathrm{FEV}_{1}$ and the Valsalva ratio $(0.39)^{37}$ and the $30: 15$ ratio $(r=0.31),{ }^{37}$ between $\mathrm{FEV}_{1}$ and LF/HF $(r=0.34)^{41}$ and LF/HFnu $(r=0.32),{ }^{26}$ and also between baroreceptor sensitivity and $\mathrm{FEV}_{1} / \mathrm{FVC}(\mathrm{r}=0.38) .{ }^{19}$ Haider et al ${ }^{19}$ reported a more moderate correlation between baroreceptor sensitivity and $\mathrm{FEV}_{1}(\mathrm{r}=0.46, P<.01)$ and also between the RRi and $\mathrm{FEV}_{1}(\mathrm{r}=0.56, P<.01)$ and $\mathrm{FEV}_{1} / \mathrm{FVC}(\mathrm{r}=$ $0.53, P<.01)$. Similarly, Bir et a ${ }^{17}$ revealed a moderately strong relationship between $\mathrm{FEV}_{1} / \mathrm{FVC}$ and latency $(\mathrm{r}=$ -0.47), amplitude $(\mathrm{r}=0.41)$, and area $(\mathrm{r}=0.40)$ and between percent-of-predicted $\mathrm{FEV}_{1} / \mathrm{FVC}$ and latency $(\mathrm{r}=$ $-0.64)$, amplitude $(\mathrm{r}=0.52)$, and area $(\mathrm{r}=0.52)(P<$ $.05)$.

Only one study of low methodological quality reported the influence of breathing frequency on autonomic function in subjects with COPD. ${ }^{28}$ The study results showed that both LF and HF were significantly correlated with breathing frequency ( $\mathrm{r}=-0.76$ and -0.70 , respectively) and ventilatory effort $(\mathrm{r}=-0.52$ and -0.49 , respectively) in subjects with COPD.

Seven studies of low ${ }^{10,26,30}$ and high ${ }^{17,34,37,45}$ methodological quality investigated the relationship between arterial blood gas parameters $\left(\mathrm{P}_{\mathrm{aO}}, \mathrm{P}_{\mathrm{aCO}}, \mathrm{pH}\right.$, and arterial oxygen saturation) and autonomic function parameters in subjects with COPD. Most of these studies demonstrated that arterial blood gas parameters did not significantly cor- relate with autonomic function. Tug et al ${ }^{45}$ reported that both $\mathrm{P}_{\mathrm{aO}_{2}}$ and $\mathrm{P}_{\mathrm{aCO}}$ did not significantly correlate with sympathetic skin response and $\mathrm{RRi}(P>.05)$. Antonelli Incalzi et $\mathrm{al}^{26}$ also reported that there was no significant correlation between $\mathrm{P}_{\mathrm{aO}_{2}}$ and $\mathrm{LF} / \mathrm{HFnu}$ (except for a weak but significant relationship with $\mathrm{P}_{\mathrm{aCO}_{2}}$ at nighttime, $\mathrm{r}=$ -0.29 ). Furthermore, no significant relationship was reported between sympathetic skin response and $\mathrm{P}_{\mathrm{aCO}_{2}}, \mathrm{P}_{\mathrm{aO}}$, $\mathrm{O}_{2}$ saturation, and $\mathrm{pH}^{17}$; between baroreceptor sensitivity and $\mathrm{P}_{\mathrm{aO}_{2}}{ }^{10}$; and between heart rate variability (variability triangular index, $\mathrm{pNN}_{50}$, and $\mathrm{HF}$ ) and $\mathrm{P}_{\mathrm{aCO}_{2}}, \mathrm{P}_{\mathrm{aO}}$, and pH. ${ }^{37}$ However, 2 studies of high methodological quality reported significant correlations between $\mathrm{P}_{\mathrm{aO}_{2}}$ and $\mathrm{HFnu}$ $(r=-0.60)$, LFnu $(r=0.44)$, and LF/HF $(r=0.37)^{34}$ and between $\mathrm{P}_{\mathrm{aO}_{2}}$ and the Valsalva ratio $(\mathrm{r}=0.27)$ and 30:15 ratio $(r=0.29) .{ }^{37}$ Moreover, significant correlations were reported between the alveolar volume transfer factor and $30: 15$ ratio $(\mathrm{r}=0.36)$ and also between the mean pulmonary artery pressure and Valsalva ratio $(r=-0.33){ }^{37}$

Two studies assessed the influence of dyspnea on autonomic function in subjects with COPD. ${ }^{2,26}$ One study (high methodological quality) showed a significant relationship between all domains of dyspnea and RMSSD $(-0.45<$ $\mathrm{r}<-0.48, P<.05$ ). ${ }^{2}$ However, the other study (low methodological quality) was unable to demonstrate any significant correlation between dyspnea and LF/HFnu $(P>$ $.05){ }^{26}$ Based on the quality and level of evidence of the studies, the evidence supporting the influence of pulmonary function, arterial blood gas, and dyspnea on autonomic function in subjects with COPD is inconsistent.

Physical Activity, Physical Fitness, and Body Composition. Five studies of $\operatorname{low}^{26}$ and high ${ }^{1,2,8,45}$ methodological quality reported the relationship between autonomic function and physical activity, physical fitness, and exercise capacity in subjects with COPD. Camillo et al ${ }^{1}$ concluded that total daily energy expenditure, daily energy expenditure in activities requiring $>3$ metabolic equivalents, number of steps/d, and time spent daily in activities demanding $>3$ metabolic equivalents significantly affected SDNN $(0.36<\mathrm{r}<0.60, P<.05)$. The energy expenditure also correlated with the SDNN index $(\mathrm{r}=0.60, P=$ $.003)$ and $\mathrm{LF} / \mathrm{HF}(\mathrm{r}=0.36, P<.05)$. Furthermore, they also found significant correlations between the RRi and time spent walking $(r=0.46)$ and standing $(r=0.41)$ and between the SDNN index and total score of activities of daily living $(\mathrm{r}=-0.44)$. van Gestel et $\mathrm{al}^{8}$ reported that there was a significant correlation between mean $\mathrm{NN}$ intervals and 6-min walk distance $(\mathrm{r}=0.43)$ and physical activity levels $(r=0.42)$. However, no correlation was reported between mean NN intervals and peak oxygen uptake and maximum work load $(P>.05)$. Similarly, the time spent walking/d was significantly correlated with heart rate variability $(\mathrm{r}=0.47, P<.05) .^{2}$ In another study, loss 
of activities of daily living was significantly correlated with LF/HFnu ( $\mathrm{r}=-0.41, P=.003)$, in addition to a weak relationship that was reported between functional status and LF/HFnu analysis over $24 \mathrm{~h}(\mathrm{r}=0.29)$ and in the daytime $(r=0.29) .{ }^{45}$ Conversely, a study of low methodological quality reported that there was no significant relationship between exercise capacity and LF/HFnu in subjects with COPD. ${ }^{26}$

The influence of muscle force and muscle strength on autonomic function in COPD was reported in 3 studies of high methodological quality. ${ }^{1,2,36} \mathrm{SDNN}$ significantly correlated with the biceps brachii $(\mathrm{r}=0.61)^{2}$ and triceps brachii $(r=0.56)$ muscle force, ${ }^{2}$ and the quadriceps and triceps muscle force also correlated with SDNN and LF/HF $(0.37>\mathrm{r}<0.44, P<.05)$ in another study. ${ }^{1}$ Furthermore, inspiratory muscle weakness was significantly associated with $\Delta \mathrm{IE}(\mathrm{r}=0.60){ }^{36}$

Only one study reported the relationship between body composition and autonomic function. ${ }^{1}$ The results revealed that there was a significant relationship between body mass index and SDNN $(r=0.44)$ and RRi $(r=0.37)$ and also between fat-free mass and SDNN $(r=0.49)$ and LF/HF $(r=0.40)$. However, no significant correlation was reported between heart rate variability and total fat mass $(P>.05)$. Based on the quality and level of evidence of the studies, there is strong evidence to support the influence of physical activity level and muscle function (force and strength) on autonomic function in subjects with COPD, but only limited evidence to support the influence of body composition.

Sociodemographic Variables. Four studies of high methodological quality reported the relationship between QOL and autonomic function. ${ }^{1,2,5,44}$ The results showed inconsistent findings. Significant relationships were reported between QOL and RMSSD $(\mathrm{r}=0.34, P=.01),{ }^{5} \operatorname{SDNN}(\mathrm{r}=$ $0.54, P=.02),{ }^{44} \mathrm{RRi}(\mathrm{r}=-0.38, P<.05),{ }^{1} \mathrm{HF}(\mathrm{r}=0.35$, $P=.01),{ }^{5}$ and $\mathrm{LF} / \mathrm{HF}(\mathrm{r}=-0.40, P<.05) .{ }^{5}$ However, in 2 studies, there were no significant correlations $(P>.05)$ between QOL and several heart rate variability parameters. ${ }^{1,2}$ In a similar trend, the relationship between age and autonomic function in subjects with COPD was reported in 3 studies of high methodological quality. ${ }^{32,41,45}$ In one of the studies, the results indicated that there was a significant correlation between age and LF/HF $(r=-0.32$, $P=.044),{ }^{41}$ whereas the other 2 studies reported that age was not significantly associated with LF/HFnu $(P>.05)^{32}$ and autonomic function $(P>.05) .{ }^{45}$

The influence of cigarette smoking on autonomic function in COPD subjects was investigated in 3 studies of low $^{27}$ and high ${ }^{1,45}$ methodological quality. Despite this, no correlation was found between smoking and RMSSD, ${ }^{1}$ baroreceptor sensitivity, ${ }^{27}$ sympathetic skin response, ${ }^{45}$ and RRi. ${ }^{45}$ Also, one study of high methodological quality on the influence of anxiety on autonomic function revealed that anxious subjects with COPD had impaired SDNN and HF values compared with nonanxious subjects $(P<.05){ }^{6}$

Based on the quality and level of evidence of the studies, the evidence supporting the influence of QOL and age on autonomic function is inconsistent. Furthermore, there is strong evidence to support that smoking does not influence autonomic function, and there is limited evidence to support the influence of anxiety on autonomic function in subjects with COPD.

Time of Day (Circadian Rhythm). Four studies of low 26 and high ${ }^{4,41,46}$ methodological quality reported the influence of circadian rhythm on autonomic function in subjects with COPD. The results from the study of Bédard et $\mathrm{al}^{41}$ showed that subjects with COPD had reduced LF/HF ratios (median and interquartile range) compared with healthy controls during the daytime (2.6 [1.5-3.8] vs 3.5 [2.9-5.6]), nighttime (1.8 [1.1-4.3] vs 4.2 [2.7-6.9]), and the entire $24-h$ period $(1.9[1.5-3.4]$ vs 3.9 [3.2-5.6]) $(P<$ $.005)$. In another study, SDNN $(P=.02)$ and SDANN $(P=.02)$ measured at nighttime were significantly higher compared with daytime values in subjects with COPD. ${ }^{46}$ Similarly, time-dependent fluctuations in heart rate variability parameters were reported in subjects with COPD, which were significantly reduced during morning periods compared with night periods $(P<.001) .{ }^{4}$ Antonelli Incalzi et $\mathrm{al}^{26}$ also reported that subjects with COPD showed fluctuations in VLF during 24-h and daytime periods and also lower LFnu, higher HFnu, and lower LF/HFnu during the daytime compared with the nighttime (all $P<.05$ ). Based on the quality and level of evidence of the studies, there is strong evidence to support that circadian rhythm influences autonomic function in subjects with COPD.

\section{Discussion}

The objective of this systematic review was to determine the level of evidence for autonomic function and its influencing factors in subjects with COPD. This was the first attempt to provide concise information and a systematic review of evidence on autonomic function in subjects with COPD. Our review included 33 studies comprising about 1,000 subjects with COPD. Additionally, the results of this review have provided a more global representation of the several parameters that make up autonomic function in these studies.

The results of this review showed that the heart rate variability time-domain parameters were significantly lower in subjects with COPD in most of the studies. In general, it would appear that this reduction in heart rate variability timing may be an indication of a problem with time series of normal RRi in subjects with COPD. This may also imply that these subjects have a lower autonomic 
activity level compared with healthy controls. Consequently, the time domain could readily serve as a yardstick for ascertaining autonomic function. Moreover, time-domain indexes of heart rate variability have been reported to be of independent prognostic significance..$^{47}$

On the other hand, frequency-domain heart rate variability parameters revealed a more conflicting outcome. The findings ranged from lower to comparable and even higher values for LF, HF, LFnu, HFnu, LF/HF, and TP variables in subjects with COPD compared with healthy controls. Consequently, evidence supporting impaired frequency-domain parameters could not be ascertained. The results obtained with the frequency-domain parameters tend to suggest, for these variations and inconsistencies, that they are random and may not provide the best means for stratification. However, there appears to be a preponderance of lower LF presentations in subjects with COPD. This may be an indication of sympathetic tone dominance, as earlier reported in chronic diseases that are closely linked with cardiovascular death. ${ }^{48,49}$ Therefore, in view of our results, time-domain analyses may provide a better interpretation and prognostic value compared with frequencydomain analyses for patients with COPD. Moreover, Lanza et $\mathrm{al}^{50}$ demonstrated that there is a strong association between low time-domain heart rate variability and mortality. They further stated that little data are available regarding the prognostic value of frequency-domain heart rate variability analysis.

In this review, we also found strong evidence in support of baroreceptor sensitivity depression in subjects with COPD. The baroreflex mechanism plays a key role in cardiovascular function, especially in the short-term regulation of blood pressure in normal and pathological conditions. ${ }^{51,52}$ The possible contributors to the depression in baroreceptor sensitivity include intrathoracic pressure changes, hypoxia, and oxidative stress. ${ }^{5}$ Moreover, these are regular features of COPD. Therefore, it is not surprising that baroreceptor sensitivity was impaired even in subjects with mild COPD. ${ }^{10,19,27}$ Our review has shown that even during early stages of COPD, baroreceptor sensitivity is impaired. Hence, it can be utilized as a reliable marker by clinicians who are presented with patients with COPD for a more comprehensive intervention.

The results from 3 studies showed that muscle sympathetic nerve activity was considerably higher (reflection of increased sympathetic excitation) in subjects with COPD compared with their healthy counterparts. ${ }^{31-33}$ Furthermore, like baroreceptor sensitivity, muscle sympathetic nerve activity is significantly associated with some features of COPD, such as decreased oxygen concentration, impairment in baroreceptor sensitivity (through the inhibitory afferent systems), high oxidative stress, and systemic inflammation.,53-55 Moreover, our review also found ele- vated muscle sympathetic nerve activity in normoxic subjects and in subjects with mild COPD. ${ }^{5}$

Generally, this review has shown that heart rate variability was impaired mainly in the time-domain parameters in subjects with COPD. Similarly, the same outcome was found for baroreceptor sensitivity and muscle sympathetic nerve activity, thereby enhancing the inference that can be drawn from our results. Our review also found that fewer studies have reported variables (baroreceptor sensitivity and muscle sympathetic nerve activity) other than heart rate variability (see Fig. 2). Moreover, only one study reported the sympathetic skin response parameter. ${ }^{14}$ However, it is very likely that the sympathetic skin response is impaired in patients with COPD, despite limited evidence. Unlike heart rate variability, baroreceptor sensitivity, and muscle sympathetic nerve activity, the sympathetic skin response assesses the sudomotor function of unmyelinated sympathetic fibers through electromyography. Therefore, it is noninvasive, requires less equipment, and can be easily performed (requiring less expertise), ${ }^{56,57}$ and it may provide an alternative to assess autonomic function (sympathetic). This review has shown a strong level of evidence supporting autonomic function impairment in subjects with COPD. Subsequent research can focus on providing evidence for intervention modes to enhance autonomic function in this population.

This review also focused on the influencing factors of autonomic function in subjects with COPD. For these, we categorized the influencing factors into 5 groups: disease severity features, pulmonary function and respiratory parameters, physical activity and body composition, sociodemographic variables, and circadian rhythm. This categorization made analyzing the evidence easier. The results suggest that the physical activity level (energy expenditure, duration of activities of daily living, duration of walking/d, and number of steps/d) is the major factor that may be useful in enhancing autonomic function (heart rate variability). Additionally, this may be a useful intervention strategy due to the high level of deconditioning that is a common feature in these patients. Moreover, physical activity is known to modulate the autonomic nervous system. ${ }^{10,58} \mathrm{~A}$ similar level of evidence was also reported in support of the positive association of muscle function and autonomic function. However, further studies are needed to determine the optimal mode for incorporating these parameters as key components of COPD rehabilitation.

The results from the studies in our review showed strong evidence that cigarette smoking does not influence autonomic function in subjects with COPD. This finding is at variance with earlier reports that have linked smoking with reductions in the baseline levels of vagal-cardiac nerve activity through its effect on the arterial baroreceptor-cardiac reflex response and increasing sympathetic activity through arterial pressure reductions.$^{59}$ Moreover, smoking 
is one of the major causes of COPD, and patients with COPD are required to stop smoking. The evidence for other sociodemographic circumstances was mostly conflicting, limited, or nonexistent. For example, inconsistent evidence was reported for age and QOL. No explicit reason could be deduced except for the effect of the normal physiological aging process because subjects with COPD are generally older. ${ }^{60-62}$ Our review did not find any study that reported the influence of factors such as sleep quality, fatigue, depression, and sex. Hence, further studies are needed to explore the potential links between these variables and autonomic function in subjects with COPD.

In most of the studies, the use of medication that can influence autonomic function in subjects with COPD, such as systemic sympathomimetic drugs, calcium channel blockers, $\beta$ blockers, other cardiac medications, caffeine/tea, smoking, and alcohol, were suspended before and/or during autonomic function assessment. However, in some studies, the subjects were not stopped from using their regular medications, such as anticholinergic, $\beta_{2}$ agonists, corticosteroids, aminophylline, and bronchodilators. ${ }^{4,11,27,32,36,38,40}$ Still, in other studies, medication use was completely avoided for a period of 6-24 h before autonomic function assessment. ${ }^{17,29,34,39}$ Nevertheless, these variations in medication use are not likely to affect our results because none of the studies included medications that could have had any significant effect on the autonomic nervous system. We also noticed differences in heart rate variability assessment procedures across the studies. The differences were mostly in terms of number of RRi points utilized in the heart rate variability analysis. In some studies, a detailed description of the setting was given, whereas in others, this was not the case. On a general note, however, the analyses were reliable to draw conclusions for both time- and frequency-domain heart rate variability because all of the procedures were standardized and reproducible. For baroreceptor sensitivity assessment, a more uniform procedure was also observed in the studies. Electrocardiogram monitoring was done in a rested and recumbent position, systolic blood pressure was continuously measured using the cuff technique, and the limb lead with the greatest $\mathrm{R}$ waves was used for assessment. ${ }^{10,11,27}$ The muscle sympathetic nerve activity assessment also utilized the same modalities and protocol. ${ }^{31-33}$

The results of our review also had some demographic variations. Slightly more than half of the participants (except for 3 studies that did not provide information on $\operatorname{sex}^{10,28,30}$ ) were males (524 of 1,000). Moreover, COPD is traditionally known to be more common in males than in females. ${ }^{63}$ Also, few studies included subjects who were not clinically stable and/or free from comorbidities that may have had an effect on autonomic function. Moreover, the subjects also presented with diverse COPD disease stages in the studies. However, the checklist that was used to grade the study quality took these points into consideration. Additionally, the majority of the studies included mainly subjects with moderate COPD; only a few included subjects with mild, ${ }^{10,19,27}$ severe, $, 1,2,28,40,46$ and mixedstage $^{5,13,17,29,37}$ COPD. Consequently, our results could be a global reflection of the general autonomic function trend in subjects with COPD.

The major limitation of this review is the general lack of blinding across the studies, perhaps due to the technical and cumbersome nature of assessing autonomic function in a laboratory setting. However, we used a standardized methodological quality-rating approach $(>60 \%$ for high quality), which showed that the most of the studies had high scores, thus providing a firm base for our results. In addition, a few of the studies had small sample sizes. ${ }^{3,11,35,36,38}$ Also, the quality assessment criteria used in arriving at the results in this review did not take the sample size of the studies into account. However, the results for heart rate variability parameters are likely to be reliable because of the large number of studies (some with very large samples) that were reviewed. For muscle sympathetic nerve activity and baroreceptor sensitivity, the sample sizes were comparatively smaller. However, this would not likely change the results due to the feasibility of recording a larger sample because the study procedures are not only technical, but also invasive, as in the case of muscle sympathetic nerve activity.

The findings of this systematic review are important to clinicians and other health-care providers given the high evidence backing our conclusion and the more concise information we presented. Moreover, this review has highlighted specific and important physiological markers that should be taken into consideration for prognostication, stratification, and management of patients with COPD. Additionally, our review can serve as a basis for future studies and reviews that will provide information on the effect of various intervention modes on autonomic function in these patients.

\section{Summary}

A strong level of evidence supports the impairment of autonomic function parameters in subjects with COPD. A similar evidence level also suggests that physical activity level, muscle function, and circadian rhythm significantly influence autonomic function and may play a role in autonomic function modulation during COPD rehabilitation.

\section{REFERENCES}

1. Camillo CA, Pitta F, Possani HV, Barbosa MV, Marques DS, Cavalheri $\mathrm{V}$, et al. Heart rate variability and disease characteristics in patients with COPD. Lung 2008;186(6):393-401.

2. Camillo CA, Laburu Vde M, Gonçalves NS, Cavalheri V, Tomasi FP, Hernandes NA, et al. Improvement of heart rate variability after 


\section{Autonomic Function in Subjects With COPD}

exercise training and its predictors in COPD. Respir Med 2011; 105(7):1054-1062.

3. Carvalho TD, Pastre CM, de Godoy MF, Fereira C, Pitta FO, de Abreu LC, et al. Fractal correlation property of heart rate variability in chronic obstructive pulmonary disease. Int J Chron Obstruct Pulmon Dis 2011;6:23-28.

4. Lewis MJ, Annandale J, Lewis KE. Influence of long-term oxygen therapy on heart rate and QT time-series in hypoxic patients with chronic obstructive pulmonary disease. Clin Physiol Funct Imaging 2009;29(6):431-439.

5. van Gestel AJR, Kohler M, Steier J, Teschler S, Russi EW, Teschler H. Cardiac autonomic dysfunction and health-related quality of life in patients with chronic obstructive pulmonary disease. Respirology 2011;16(6):939-946.

6. Suh S, Ellis RJ, Sollers JJ 3rd, Thayer JF, Yang HC, Emery CF. The effect of anxiety on heart rate variability, depression, and sleep in chronic obstructive pulmonary disease. J Psychosom Res 2013;74(5): 407-413.

7. Ricci-Vitor AL, Bonfim R, Fosco LC, Bertolini GN, Ramos EMC, Ramos D, et al. Influence of the resistance training on heart rate variability, functional capacity and muscle strength in the chronic obstructive pulmonary disease. Eur J Phys Rehabil Med 2013;49(6): 793-801.

8. van Gestel AJR, Kohler M, Steier J, Teschler S, Russi EW, Teschler $\mathrm{H}$. The effects of controlled breathing during pulmonary rehabilitation in patients with COPD. Respiration 2012;83(2):115-124.

9. Borghi-Silva A, Mendes RG, Trimer R, Oliveira CR, Fregonezi GA, Resqueti VR, et al. Potential effect of 6 versus 12 weeks of physical training on cardiac autonomic function and exercise capacity in chronic obstructive pulmonary disease. Eur J Phys Rehabil Med 2015;51(2):211-221.

10. Costes F, Roche F, Pichot V, Vergnon JM, Garet M, Barthelemy JC. Influence of exercise training on cardiac baroreflex sensitivity in patients with COPD. Eur Respir J 2004;23(3):396-401.

11. Bartels MN, Gates GJ, Downey JA, Armstrong HF, De Meersman RE. Baroreceptor sensitivity after Valsalva maneuver in women with chronic obstructive pulmonary disease. Clin Auton Res 2012;22(4): 185-189.

12. Meeus M, Goubert D, De Backer F, Struyf F, Hermans L, Coppieters I, et al. Heart rate variability in patients with fibromyalgia and patients with chronic fatigue syndrome: a systematic review. Semin Arthritis Rheum 2013;43(2):279-287.

13. Dias de Carvalho T, Marcelo Pastre C, Claudino Rossi R, de Abreu LC, Valenti VE, Marques Vanderlei LC. [Geometric index of heart rate variability in chronic obstructive pulmonary disease]. Rev Port Pneumol 2011;17(6):260-265. Article in Portuguese.

14. Pagani M, Montano N, Porta A, Malliani A, Abboud FM, Birkett C, Somers VK. Relationship between spectral components of cardiovascular variabilities and direct measures of muscle sympathetic nerve activity in humans. Circulation 1997;95(6):1441-1448.

15. Shahani BT, Halperin JJ, Boulu P, Cohen J. Sympathetic skin response- a method of assessing unmyelinated axon dysfunction in peripheral neuropathies. J Neurol Neurosurg Psychiatry 1984;47(5): 536-542.

16. Robinson TG, Dawson SL, Eames PJ, Panerai RB, Potter JF. Cardiac baroreceptor sensitivity predicts long-term outcome after acute ischemic stroke. Stroke 2003;34(3):705-712.

17. Bir LS, Ozkurt S, Daloğlu G, Kurt T. Impaired sympathetic skin response in chronic obstructive pulmonary disease. Tohoku J Exp Med 2005;207(4):243-248.

18. van Gestel AJR, Steier J. Autonomic dysfunction in patients with chronic obstructive pulmonary disease (COPD). J Thorac Dis 2010; 2(4):215-222.
19. Haider T, Casucci G, Linser T, Faulhaber M, Gatterer H, Ott G, et al. Interval hypoxic training improves autonomic cardiovascular and respiratory control in patients with mild chronic obstructive pulmonary disease. J Hypertens 2009;27(8):1648-1654.

20. Marquis K, Maltais F, Lacasse Y, Lacourciere Y, Fortin C, Poirier P. Effects of aerobic exercise training and irbesartan on blood pressure and heart rate variability in patients with chronic obstructive pulmonary disease. Can Respir J 2008;15(7):355-360.

21. Liberati A, Altman DG, Tetzlaff J, Mulrow C, Gøtzsche PC, Ioannidis JP, et al. The PRISMA statement for reporting systematic reviews and meta-analyses of studies that evaluate health care interventions: explanation and elaboration. PLoS Med 2009;6(7): e1000100.

22. Vandenplas G, De Bacquer D, Calders P, Fiers T, Kaufman JM, Ouwens DM, Ruige JB. Endogenous oestradiol and cardiovascular disease in healthy men: a systematic review and meta-analysis of prospective studies. Heart 2012;98(20):1478-1482.

23. Franki I, Desloovere K, De Cat J, Feys H, Molenaers G, Calders P, et al. The evidence-base for conceptual approaches and additional therapies targeting lower limb function in children with cerebral palsy: a systematic review using the international classification of functioning, disability and health as a framework. J Rehabil Med 2012;44(5):396-405.

24. Himpens E, Van den Broeck C, Oostra A, Calders P, Vanhaesebrouck $P$. Prevalence, type, distribution, and severity of cerebral palsy in relation to gestational age: a meta-analytic review. Dev Med Child Neurol 2008;50(5):334-340.

25. Bakker EWP, Verhagen AP, van Trijffel E, Lucas C, Koes BW. Spinal mechanical load as a risk factor for low back pain: a systematic review of prospective cohort studies. Spine 2009;34(8): E281-E293.

26. Antonelli Incalzi R, Corsonello A, Trojano L, Pedone C, Acanfora D, Spada A, et al. Heart rate variability and drawing impairment in hypoxemic COPD. Brain Cogn 2009;70(1):163-170.

27. Bernardi L, Casucci G, Haider T, Brandstätter E, Pocecco E, Ehrenbourg I, Burtscher M. Autonomic and cerebrovascular abnormalities in mild COPD are worsened by chronic smoking. Eur Respir J 2008; 32(6): 1458-1465.

28. Chang ET, Silberstein D, Rambod M, Porszasz J, Casaburi R. Heart rate variability during constant work rate exercise at and above the critical power in patients with severe chronic obstructive pulmonary disease. Tzu Chi Med J 2011;23(2):42-45.

29. Ramos EMC, Vanderlei LCM, Ramos D, Teixeira LM, Pitta F, Veloso M. Influence of pursed-lip breathing on heart rate variability and cardiorespiratory parameters in subjects with chronic obstructive pulmonary disease (COPD). Braz J Phys Ther 2009;13(4):288-293.

30. Yazici M, Uzun K, Ulgen MS, Teke T, Maden E, Kayrak M, et al. The acute effect of bi-level positive airway pressure on heart rate variability in chronic obstructive pulmonary disease patients with hypercapnic respiratory failure. Anadolu Kardiyol Derg 2008;8(6): 426-430.

31. Raupach T, Bahr F, Herrmann P, Luethje L, Heusser K, Hasenfuss $\mathrm{G}$, et al. Slow breathing reduces sympathoexcitation in COPD. Eur Respir J 2008;32(2):387-392.

32. Fatouleh R, Macefield VG. Respiratory modulation of muscle sympathetic nerve activity is not increased in essential hypertension or chronic obstructive pulmonary disease. J Physiol 2011;589(Pt 20): 4997-5006.

33. Raupach T, Bahr F, Herrmann P, Lüthje L, Hasenfuss G, Andreas S. Inspiratory resistive loading does not increase sympathetic tone in COPD. Respir Med 2010;104(1):107-113.

34. Chen WL, Chen GY, Kuo CD. Hypoxemia and autonomic nervous dysfunction in patients with chronic obstructive pulmonary disease. Respir Med 2006;100(9):1547-1553. 


\section{Autonomic Function in Subjects With COPD}

35. Gunduz H, Talay F, Arinc H, Ozyildirim S, Akdemir R, Yolcu M, et al. Heart rate variability and heart rate turbulence in patients with chronic obstructive pulmonary disease. Cardiol J 2009;16(6):553559.

36. Reis MS, Arena R, Deus AP, Simões RP, Catai AM, Borghi-Silva A. Deep breathing heart rate variability is associated with respiratory muscle weakness in patients with chronic obstructive pulmonary disease. Clinics 2010;65(4):369-375.

37. Chhabra SK, De S. Cardiovascular autonomic neuropathy in chronic obstructive pulmonary disease. Respir Med 2005;99(1):126-133.

38. Reis MS, Deus AP, Simões RP, Aniceto IA, Catai AM, Borghi-Silva A. Autonomic control of heart rate in patients with chronic cardiorespiratory disease and in healthy participants at rest and during a respiratory sinus arrhythmia maneuver. Rev Bras Fisioter 2010;14(2): 106-113.

39. Borghi-Silva A, Reis MS, Mendes RG, Pantoni CBF, Simões RP, Martins LEB, et al. Noninvasive ventilation acutely modifies heart rate variability in chronic obstructive pulmonary disease patients. Respir Med 2008;102(8):1117-1123.

40. Zamarrón C, Lado MJ, Teijeiro T, Morete E, Vila XA, Lamas PF. Heart rate variability in patients with severe chronic obstructive pulmonary disease in a home care program. Technol Health Care 2014; 22(1):91-98

41. Bédard ME, Marquis K, Poirier P, Provencher S. Reduced heart rate variability in patients with chronic obstructive pulmonary disease independent of anticholinergic or $\beta$-agonist medications. COPD 2010; 7(6):391-397.

42. Aggarwal S, Arora M, Kaur N, Bachhal R, Sidhu RS. Autonomic nervous system changes in chronic obstructive pulmonary disease (COPD) patients. J Clin Diagn Res 2011;5(8):1533-1536.

43. Rossi RC, Vanderlei FM, Bernardo AF, Souza NM, Gonçalves AC, Ramos EMC, et al. Effect of pursed-lip breathing in patients with COPD: linear and nonlinear analysis of cardiac autonomic modulation. COPD 2014;11(1):39-45.

44. Zupanic E, Zivanovic I, Kalisnik JM, Avbelj V, Lainscak M. The effect of 4-week rehabilitation on heart rate variability and QTc interval in patients with chronic obstructive pulmonary disease. COPD 2014;11(6):659-669.

45. Tug T, Terzi SM, Yoldas TK. Relationship between the frequency of autonomic dysfunction and the severity of chronic obstructive pulmonary disease. Acta Neurol Scand 2005;112(3):183-188.

46. Sin DD, Wong E, Mayers I, Lien DC, Feeny D, Cheung H, et al. Effects of nocturnal noninvasive mechanical ventilation on heart rate variability of patients with advanced COPD. Chest 2007;131(1):156163.

47. Zuanetti G, Neilson JM, Latini R, Santoro E, Maggioni AP, Ewing DJ. Prognostic significance of heart rate variability in post-myocardial infarction patients in the fibrinolytic era. The GISSI-2 results. Gruppo Italiano per lo Studio della Sopravvivenza nell' Infarto Miocardico. Circulation 1996;94(3):432-436.
48. Pal GK, Pal C, Adithan C, Ananthanarayanan PH, Pal P, Nanda N, et al. Sympathovagal imbalance contributes to prehypertension status and cardiovascular risks attributed by insulin resistance, inflammation, dyslipidemia and oxidative stress in first degree relatives of type 2 diabetics. PLoS ONE 2013;8(11):e78072.

49. Huikuri HV, Mäkikallio T, Airaksinen KEJ, Mitrani R, Castellanos A, Myerburg RJ. Measurement of heart rate variability: a clinical tool or a research toy? J Am Coll Cardiol 1999;34(7):1878-1883.

50. Lanza GA, Guido V, Galeazzi MM, Mustilli M, Natali R, Ierardi C, et al. Prognostic role of heart rate variability in patients with a recent acute myocardial infarction. Am J Cardiol 1998;82(11):1323-1328.

51. Tank J, Diedrich A, Szczech E, Luft FC, Jordan J. Baroreflex regulation of heart rate and sympathetic vasomotor tone in women and men. Hypertension 2005;45(6):1159-1164.

52. Gmitrov J. Static magnetic field effect on cardiovascular regulation: a review. Br J Med Med Res 2014;4(8):1612-1627.

53. Bernardi L, Porta C, Spicuzza L, Bellwon J, Spadacini G, Frey A, et al. Slow breathing increases arterial baroreflex sensitivity in patients with chronic heart failure. Circulation 2002;105(2):143-145.

54. Gerritsen J, Dekker JM, TenVoorde BJ, Kostense PJ, Heine RJ, Bouter LM, et al. Impaired autonomic function is associated with increased mortality, especially in subjects with diabetes, hypertension, or a history of cardiovascular disease: the Hoorn Study. Diabetes Care 2001;24(10):1793-1798.

55. Charkoudian N, Rabbitts JA. Sympathetic neural mechanisms in human cardiovascular health and disease. Mayo Clin Proc 2009; 84(9):822-830

56. Vetrugno R, Liguori R, Cortelli P, Montagna P. Sympathetic skin response. Clin Auton Res 2003;13(4):256-270.

57. Gutrecht JA. Sympathetic skin response. J Clin Neurophysiol 1994; 11(5);519-524.

58. Nagai N, Moritani T. Effect of physical activity on autonomic nervous system function in lean and obese children. Int $\mathrm{J}$ Obes Relat Metab Disord 2004;28(1):27-33.

59. Niedermaier ON, Smith ML, Beightol LA, Zukowska-Grojec Z, Goldstein DS, Eckberg DL. Influence of cigarette smoking on human autonomic function. Circulation 1993;88(2):562-571.

60. O'Brien IA, O'Hare P, Corrall RJ. Heart rate variability in healthy subjects: effect of age and the derivation of normal ranges for tests of autonomic function. Br Heart J 1986;55(4):348-354.

61. Liao D, Barnes RW, Chambless LE, Simpson RJ Jr, Sorlie P, Heiss G. Age, race, and sex differences in autonomic cardiac function measured by spectral analysis of heart rate variability-The ARIC study. Am J Cardiol 1995;76(12):906-912.

62. van Durme YM, Verhamme KM, Stijnen T, van Rooij FJ, Van Pottelberge GR, Hofman A, et al. Prevalence, incidence, and lifetime risk for the development of COPD in the elderly: the Rotterdam study. Chest 2009;135(2):368-377.

63. Mannino DM, Buist AS. Global burden of COPD: risk factors, prevalence, and future trends. Lancet 2007;370(9589):765-773. 